to suggest that in the main we officiously keep people alive has never been true. To insinuate that we do not find out the wishes of the patients at appropriate times is equally untrue. To imply that something written six months previously should dictate what we do today is simply foolish. To recommend we take it into account is certainly what we do in the hospice world and, I am sure, in the main, elsewhere.

Most doctors work well with their patients and the patients' relatives at these difficult times, but many of us feel that it is right that we may be asked to account for our actions in a court of law. It seems that they are already having problems in the Netherlands. ${ }^{2}$

This long debate on euthanasia and advanced directives has stimulated a great deal of rethinking and has brought to light many very useful ways forward for the profession and alerted patients to the need for good communication with their physicians. I hope that many feel, as I do, that we cannot simply legislate these difficulties away. I believe that the public opinion surveys show that the majority support the principle of caring, not legislation.

St Barnabas Hospice,

RA CATTERALL Lincoln LN2 1RE

Medical director

1 Simms M. Ethics and euthanasia. BMf 1994;308:1165. (30 April.)

2 Sheldon T. Dutch prosecutors get tough on euthanasia. $B M F$ 1994;308:1119-20. (30 April.)

\section{Clinical oncology information network}

EDITOR,-M C Gulliford suggests that the Royal College of Radiologists has dismissed the use of population based registries for evaluating treatment of cancer. ${ }^{1}$ Many registries have incomplete data that have been extracted by clerks from inadequate hospital case notes. In Gulliford $e t a l \mathrm{~s}$ study of bladder cancer the rate of discrepancies between cancer registry data and hospital case notes was $17 \%$ for the date of first operation, $12 \%$ for the date of first radiotherapy and $16 \%$ for the radiotherapy dose. ${ }^{2}$ Only $15 \%$ of patients receiving chemotherapy were recorded as such in the registry; $28 \%$ of the case notes gave no data on pathological tumour stage. There was also confusion regarding the classification of superficial and invasive bladder cancers. Another major confounding factor is that important prognostic factors may not be recorded either in cancer registration data or in cancer treatment centres.

The clinical oncology information network project intends to address these problems by seeking national agreement on the type of data to be collected. ${ }^{3}$ Equally important is the assignment of precise definitions to data. Körner statistics record the number of "new patients" seen, but there is no agreed definition of a new patient. The Royal College of Radiologists recognises that patients treated in cancer centres are only a subset of the population with cancer as a whole.

Ian Basnett and colleagues urge us to improve our current systems. ${ }^{4}$ The clinical oncology information network project intends that information on patients with cancer will be captured at clinical workstations integrated into the usual working conditions of clinical oncologists and their staff. This should help to improve the accuracy and completeness of data acquired and eliminate transcription errors. Cancer registry data would be produced as a byproduct.

The secretary of state for health owns case records. The Royal College of Radiologists will own the summary data used for national comparative audit. To secure the cooperation of the medical profession, participants in the clinical oncology information network must be satisfied that the data will be used appropriately. The use of data in computer systems compliant with the network would not be restricted by the Royal College of Radiologists.

Basnett et al compared process and outcome in a teaching and a non-teaching district. ${ }^{5}$ The teaching district did more scans and had a significant, $20 \%$ better survival rate at five years. The largest difference that might be expected to result from treatment is $10 \%$. The discrepancy probably results from stage migration: if more investigations that detect metastases are carried out patients wil be reclassified from a lower to a higher stage. With increasing numbers of tests the prognosis at all stages improves. This will constantly confound comparative audit. The clinical oncology information network will address this by achieving agreement among oncologists on the definition of stages and by analysing groups assigned stages according to the definition even if additional tests are done. Basnett et al's study compared practice in two districts between 1982 and 1986 with consensus guidelines issued in 1986, so any conclusion drawn is probably irrelevant. Recent practice needs to be audited against contemporary guidelines that reflect a professional consensus rather than the recommendations of a consensus conference.

\section{Clinical Oncology Centre, \\ North Middlesex Hospital,}

London N18 1 QX

STEPHEN J KARP

1 Gulliford MC. Clinical oncology information network. $B M \mathcal{F}$ 1994;308:597. (26 February.)

2 Gulliford MC, Bell J, Bourne HM, Petruckevitch A. The reliability of cancer registry records. $\mathrm{Br} \mathcal{F}$ Cancer 1993;6? 819-21.

3 Karp SJ, Squire CJ. Clinical oncology information network (COIN). Clin Oncol 1994;6:5-6.

4 Basnett I, Pollock AM, Gill M. Collecting data on cancer. BMf 1994;308:791. (19 March.)

5 1994;308:791. (19 March.)
Basnett I, Gill M, Tobias JS. Variations in breast cancer management between a teaching and a non-teaching district. Eur F Cancer 1992;28A: 1945-50.

\section{Overdose of diltiazem}

EDrTOR,-In response to John Kenny's editorial on the hazards associated with calcium channel blockers in overdose ${ }^{1} \mathrm{I}$ wish to report my and colleagues' findings with respect to fatal overdose of diltiazem. ${ }^{2}$ Diltiazem is an antianginal drug that has been available in Britain since 1985. Six fatal cases of overdose have been reported..$^{24}$ It is difficult to estimate the incidence of overdose of diltiazem as only one poisons centre in Britain (the National Poisons Information Service, London) keeps a database on overdoses of this drug. Between 1983 and 1988, 14 cases of overdose of diltiazem occurred in adults and five cases of accidental ingestion occurred in children. In France, between 1979 and 1988, 83 cases of overdose occurred in adults and 51 accidental poisonings occurred in children. ${ }^{5}$ The true incidence of overdose of diltiazem is probably grossly underestimated.

As Kenny pointed out, routine drug screening for calcium channel blockers does not take place. As many of the complications of calcium channel blockers are cardiovascular in nature, cases of overdose could be missed and their clinical features assumed to be due to existing cardiovascular disease. We reviewed cases of overdose of diltiazem and attempted to correlate clinical sequelae with drug concentrations. ${ }^{2}$ The therapeutic range of concentrations was $100-200 \mu \mathrm{g} / 1$. At concentrations of $1000-1500 \mu \mathrm{g} / \mathrm{l}$ conduction abnormalities greater than first degree heart block and hypotension occurred. All patients with concentrations $>1500 \mu \mathrm{g} / \mathrm{l}$ required a temporary pacemaker, and all patients with concentrations $>6100 \mu \mathrm{g} / \mathrm{l}$ died.
If drug assays were routinely available not only could the diagnosis be made but serious side effects could be anticipated. Caution must be used, however, when drugs are taken in combination (one patient took diltiazem together with a $\beta$ blocker and died, despite intensive resuscitation, with a diltiazem concentration of $\left.1500 \mu \mathrm{g} / 1^{2}\right)$. Similar caution should be used when the patient is elderly, has severe coronary artery disease, or has any other disease that can lower the "mortality threshold." A literature review showed that the mean time for recovery in uncomplicated cases was 36 hours, allowing the withdrawal of supportive treatment.

Similar toxicological reviews for the other calcium antagonists would be useful to determine the drug concentrations at which complications are likely to occur. As the use and the risk of misuse of calcium channel blockers increase there will be an increasing need to assay these drugs in acute cases.

TA ROPER

Ladywell Hospital, Registrar in geriatrics

Salford M5 2AA

1 Kenny J. Treating overdose with calcium channel blockers. $B M F$ 1994;308:992-3. (16 April.)

Roper TA, Sykes R, Gray C. Fatal diltiazem overdose. Postgrad Med f 1993;69:474-6.

Weise J, Klug E, Schneider V, Tenczer J, Beyer K. Tơdliche Diltiazemvergiftung. $Z$ Rechtsmed 1988;100:271-6.

Kaliciak HA, Huckin SN, Cave WS. A death attributed solely to diltiazem. F Anal Toxicol 1992;16:102-3.

5 Jaeger A, Sauder PH, Kopferschmitt J, Flesch F, Dahler M, Tritsch $L$. Intoxications aiguë par le diltiazem: etude cinétique Tritsch L. Intoxications aigue par le diltiazem: etude
et hémodynamique. $f$ Toxicol Clin Exp 1990;10:243-8.

\section{Mental health law}

EDITOR,-Responding to my paper on mental health law,' the National Schizophrenia Fellowship writes ${ }^{2}$ that it supports supervised discharge orders. ${ }^{3}$ The form that such orders might take, however, has now been called into question by the recommendation by the Clunis inquiry that, within the order, "if the responsible medical officer considers that the patient has failed to comply with the plan, or that the patient's mental health is deteriorating, the patient may be recalled to hospital."4 The Department of Health's original version of the order would allow only for urgent case review with a view to re-sectioning under the Mental Health Act if the patient was deemed detainable. Hence, in terms of coercion of the patient the Clunis inquiry's recommendation goes further than both the department's proposal and the community supervision order recommended by the Royal College of Psychiatrists ${ }^{5}$ by contructing what amounts to conditional discharge. If enacted in relation to patients who are not offenders such an order might be open to challenge in the European Court of Human Rights.

Officers of the Royal College of Psychiatrists point to apparent inaccuracies in my statements about examination in mental health law of candidates for the MRCPsych. ${ }^{2}$ I did not intend to suggest that the subject was not examined at all. I wrote, "the college does not formally examine in mental health law." Hence, although very general legal questions can potentially be set in the written examination, the college does not currently think that specific legal provisions can be examined. I believe that this has given rise to the belief among candidates that the subject is not examined at allshown by reported "patchy knowledge."2 Otherwise, more specific examination rests on both a chance meeting between an oral examiner and candidate from the same legal jurisdiction and the wish of the examiner to examine the subject. I am sorry that I did not qualify the statement more clearly. The officers' assertion that "there is no dispute between the college and Irish candidates" is correct, and I regret it if the reverse could have been an interpretation of my words. I believe that the college did stop written examination of specific 